\title{
Development of finite element computer code for thermal analysis of roller compacted concrete dams
}

\begin{abstract}
Thermal analysis of roller compacted concrete (RCC) dams plays an important role in their design and construction. This paper deals with the development of a finite element based computer code for the determination of temperatures within the dam body. The finite element code is then applied to the real full-scale problem to determine the impact of the placement schedule on the thermal response of roller compacted concrete dam. Based on the results obtained, it could be concluded that for a given roller compacted concrete dam, changing the placing schedule can optimize the locations of maximum temperature zones.
\end{abstract}

Keyword: RCC dams, Birth, Death, Thermal analysis, Field problems, Schedule of construction, Finite element 